\title{
Gaps in Doctor-Patient Communication: Doctor-Patient Interaction Analysis
}

\author{
barbara Freemon, Vida F. Negrete, Milton Davis, and Bariara M. Korschi \\ Department of Pediatrics, Childrens Hospital of Los Angeles, Unisersity of Southern California \\ School of Medicine, Los Angeles, California, US.I
}

\begin{abstract}
Extract
As one of several approaches to scientific analysis of doctor-patient communication, 285 visits to a pediatric walk-in clinic were scrutinized using an expanded version of Bales' Interaction Process Analysis. Data analysis consisted of individual case studies and computer programs for descriptive summaries of cases and index scores. Factor analysis and chi-square calculations were among the methods used to test significant relations between attributes of the doctor-patient interaction and the dependent variables, patient satisfaction, compliance, and demography.

As hypothesized, a distinctive behavior pattern emerged for doctor, parent, and child. Doctors were found to talk more but show less emotion than mothers. Almost two-thirds of the mother's communication related to medical history, while the doctor discussed history and treatment but gave little attention to cause, prognosis, and seriousness. Although the physician expressed relatively little reassurance or friendliness to the mother, almost half of his conversation with the child consisted of friendly statements. In general, outcome of the medical consultation was found to be favorably influenced by having a physician who was friendly, expressed solidarity, took some time to discuss nonmedical, social subjects, and gave the impression of offering information freely without the patients having to request it or feeling excessively questioned.
\end{abstract}

\section{Speculation}

Because of the complicated nature and limited methods available for study, the doctorpatient relation has rarely been subjected to scientific inquiry or attempts at quantification. It is hoped that the present effort as well as other ongoing studies will contribute to a body of scientific information which in itself may have application for pediatric education and practice and which ultimately might contribute one approach in urgently needed studies of the cquality of medical care.

\section{Introduction}

The art of interviewing patients has been the subject of many books and articles by liealth professionals and behavioral scientists. Most experienced physicians bclieve themselves expert in "medical history taking," "bedside manner," and the "art of medicine," and they cherish the patterns of doctor-patient relation that they have evolved. The teaching of students and young physicians is usually done by their more experienced colleagues on the basis of intuition, precept, and personal preferences. Advice to the inexperienced interviewer tends to stress the importance of creating a friendly atmosphere, taking plenty of time to establish 


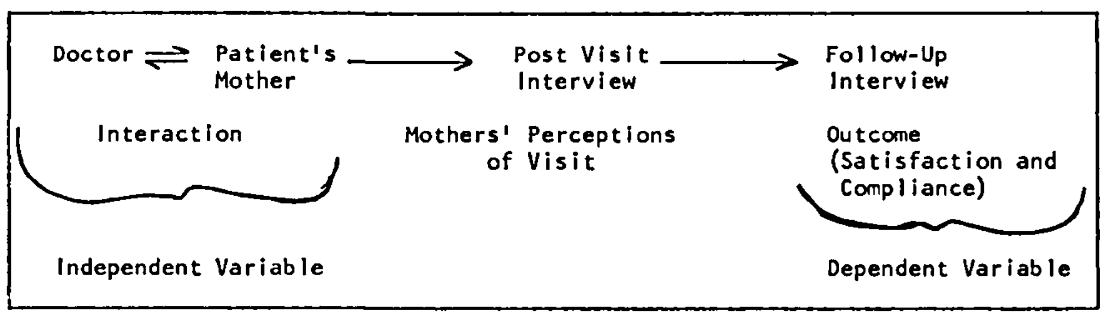

Iig. 1. Research design.

rapport with the patient, not being too directive and authoritarian but being willing to listen to the patient's concerns. All these seem reasonable tenets on the basis of humanism, common sense, and clinical experience, but one is tempted to ask the question that has come to be legendary in respect to the rest of medical knowledge, namely, "What is the evidence?", that these approaches to interviewing are the ones that lead to the most effective medical care.

This third in a series of papers $[12,17]$ from a 3-year research project on doctor-patient communication will focus on role enactment $[13,22]$ - how the doctor and patient (in pediatrics, the parent) behave in relation to each other-and the types of behavior that relate to patient satisfaction and compliance. It was postulated that a distinctive behavior pattern would emerge for doctor, parent, and child and that a relation would be found between the nature of the communication and the outcome of the visit.

\section{Method}

The methods used in this investigation and the findings concerning outcome, as determined by interviews with the parent, have been reported previously $[12,14$, 17]. Two hundred eighty-five patient visits were studied by means of tape recording the medical consultation, by chart review, and by follow-up interviews with mothers (Fig. 1). Two control groups were obtained to measure possible effects of tape recording and interviewing so that the entire sample totaled 800 .

The findings presented must be considered in light of the fact that the unit for study was an initial visit for an acute illness in the outpatient department of a childrens hospital and the pediatricians observed were usually members of the house staff with $1-4$ years pecliatric experience.

\section{Interaction Categories}

For analysis of the tape-recorded interaction Bales' Interaction Process Analysis [3] was chosen because it allowed for quantification of the interaction into dis-
Table I. Modified Bales categorics for interaction analysis ${ }^{1}$

\begin{tabular}{ll}
\hline Positive affect & 1. Friendliness, shows solidarity. \\
& 2. Shows tension release, jokes, laughs. \\
& 3. Agreement and/or understanding. \\
3a. Simple attention. \\
Neutral & 4. Gives instructions. \\
statements & 5. Gives opinion. \\
& 6. Gives information. \\
Neutral & 7a. Introductory, parenthetical expressions. \\
questions & 8. Asks for information. \\
& 9. Asks for instructions. \\
Negative & 10. Disagres. \\
affect & 11. Shows tension.
\end{tabular}

'For clarity the description of Bales categories has been simplified. The index in Interaction Process Analysis [3] contains the complete definitions.

tinctive units designed to capture the nature of the communication process itself. In addition, this method enabled the interaction data to be compared with other variables in this study as well as with other studies $[10,11]$. Besides process analysis, records were kept of the content being discussed: history, physical examination, diagnosis, cause, seriousness-prognosis, treatment, or nonmedical conversation.

As shown in Table I, the Bales categories divide conversation into statements of positive, neutral, and negative "affect"; because of the medical nature of the visits, slight modifications were made in those originally proposed by Bales. Highly positive statements expressed warmth, friendliness, solidarity, and empathy; e.g., "Hello, Don't worry, She'll be all right," and/or raised the other's status by means of praise or respect; e.g., "You're doing a good job with Mary." Tension release usually occurred in the form of jokes, laughter, and humor. The speakers showed simple attention by a yes or hum-hum which only indicated listening to what was said; strong agreement included 


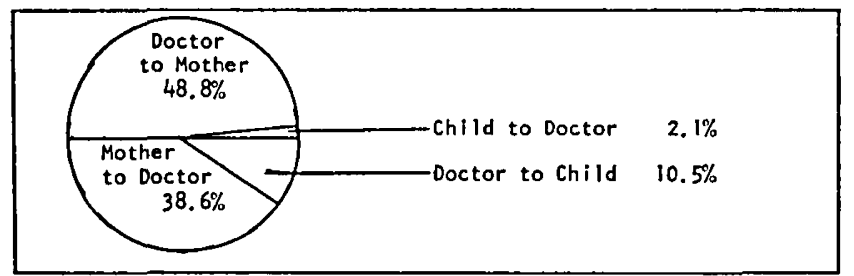

Fig. 2. Speakers' participation $(N=\mathbf{2 8 5})$.

signs of genuine understanding, agreement, or intention to comply and was coded mostly by the strongly affirmative tone of the voice.

Both questions and statements were divided into information, opinion, or instruction categories. Conversation having a negative tone was coded under one of the following areas: mild disagrecments-coolness, detachment, withholding of help, interruptions; antagonism-anger, threats, discourtesy, criticism, and hostility; or tension-worry, nervous laughter, anxiety, asking for help, showing distress or pain.

\section{Coding}

Because of the interpretive nature of the codes, a team of two persons audited the tape recording but coded each interaction on transcribed copies independently and then came to mutual agreement on the most suitable codes. Coding reliability was checked periodically and averaged $81 \%$ interteam agreement on the modified set of Bales categories and $84 \%$ when these were collapsed to the original 12. For the content, coding reliability was $85 \%$. From the code sheets all data were keypunched, stored on magnetic tape, and compiled by computer.

\section{Satisfaction and Compliance Ratings}

Since this report relates compliance and satisfaction ratings to interaction data, the derivation of these ratings will be explained briefly. A detailed description has been published elsewhere [12, 17]. Satisfaction ratings were based on a combination of "global" impressions recorded by experienced interviewers in the field, responses to questions in the interview that addressed themselves directly to satisfaction ("How satisfied were you with your visit?"), and questions that indirectly sought out satisfaction ("What were some of the things you did not like about your visit with the doctor?"). Of the 800 mothers, $76 \%$ were satisfied and $24 \%$ dissatisficd. Likewise, patients were placed in one of three categories depending on their compliance with the doctor's prescriptions or in a no regimen category. Fortytwo percent of the patients carried out all the doc- tors instructions (high compliance), $11 \%$ carried out little or none (low compliance), and $38 \%$ followed the medical regimen in part (moderate compliance).

\section{Results}

The 285 interactions ranged in length from 22 to 1206 statements with an average of 229. As illustrated in Fig. 2, doctors talked more than mothers, 48.8 and $38.6 \%$, respectively. Considering each case inclividually, $14 \%$ of the mothers talked more than the doctor, $27 \%$ the same amount, and $59 \%$ talked less than the doctor. Communication between the doctor and child consumed, on the average, $12.5 \%$ of the total interaction units.

\section{Role Profiles}

Although the most common patterns of bchavior for mother, doctor, and child are represented in composite profiles summarizing the 285 interactions, it must be emphasized that there were also individual patterns which differed dramatically. Discussion between mother and doctor (Fig. 3) included little warm, friendly, positive affect; i.e., those statements which, in effect, attempt to bring solidarity to the interaction. More of the mothers' conversation expressed agreement with, acknowledgement, and understanding of what was being said than did the doctors'.

Differences between the mother and doctor role are evident in the neutral categories: making statements and asking questions (Fig. 3, categories 4-9). The doctor gave most of the instructions and the mothers asked for some but not as many instructions as might be expected. Perhaps the medical consultation itself represents an implicit request for help from mothers and therefore specific requests are not often verbalized. Although the traditional role of the doctor is to give advice and suggestions about what to do, it had been thought that doctors might encourage mothers more to take an active rolc in solving the medical problem, but evidently this docs not occur frequently. The doctor asked for suggestions from the mother in only 6 of the 285 cases. Since the mother has to provide the medical history, it was primarily the doctor who asked for information. In gencral, giving information and orientation was the most frequent type of communication for both mother (46.9\%) and cloctor (35.5\%) in the medical visits. In effect, this exchange of information meets the "task goal" of planning for the care of the sick child.

The last three categories in Figure 3 depict negative 


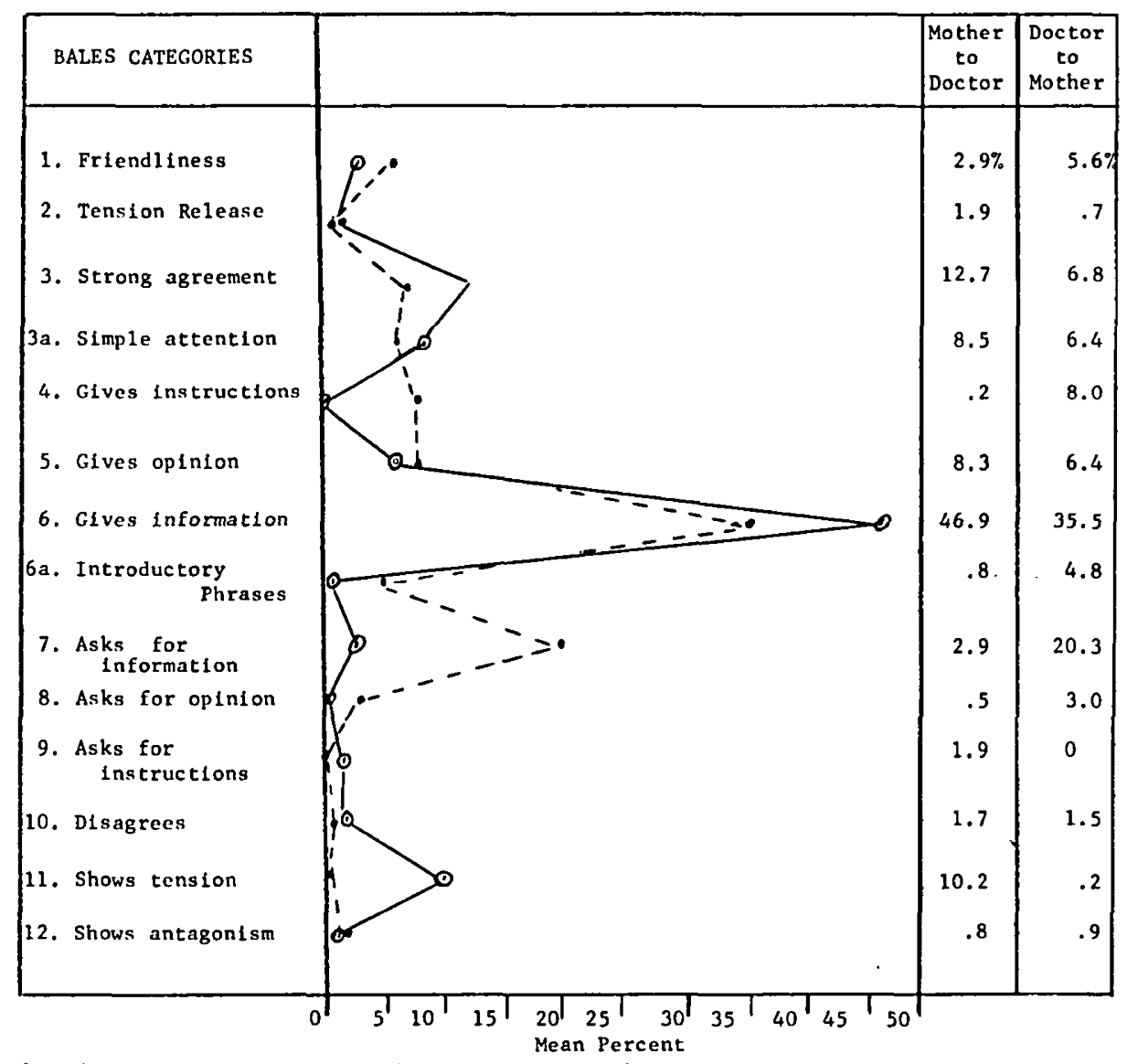

Fig..3. Mean profile of mother-doctor communication in the Bales categories. $\odot-\odot:$ Mother to doctor. $\bullet--\bullet:$ Doctor to mother.

affect. In general, mothers expressed a much higher percentage of negative affect than doctors and it was mainly passive in the form of tension, fear, or helplessness, rather than in direct attack or rejection of the doctor, the latter being more incongruous with their patient role. In contrast to doctors, expressions of tension by mothers were quite frequent, averaging $10.2 \%$ of the total statements and ranging from none to as much as $45 \%$.

The Bales category scores for mother and doctor were also studied by means of a factor analysis computer program to identify those combinations of categories which occurred spontancously and consequently to check these against the dependent variables. The three major factors that were isolated included mothcr-doctor arguments-disagrecments; friendliness-joking; and information requesting and giving. Findings suggest that a two-way exchange was necessary for an overt disagreement or argument to occur; not only was overt negativity shown to be associated for mother and doctor in the factor analysis, but the role profile (Fig. 3) points out similar mean percentages for both.
To estimate the degree of the two speakers' emotional involvement in the medical visit, the proportion of affectual statements to neutral statements was calculated. On the average, the scores were twice as high for mothers as for doctors.

The profile for the doctor-child process analysis (Fig. 1) shows the communication to fall consistently into a few categories. Almost one-half of the doctors' conversation with their child-paticnts consisted of warm, friendly statements while another quarter was concerned with giving instructions (mostly regarding the physical examination). The child talked to the doctor largely by answering his questions; by showing pain, anxiety, or anger; and by complying with his instructions.

\section{Content Categories}

The mother-doctor composite content profile (Fig. 5) illustrates that the most common subjects for discussion were history and treatment. In fact, it was during history-taking that mothers spoke the most; almost two-thirds of their communication to the doctor was 


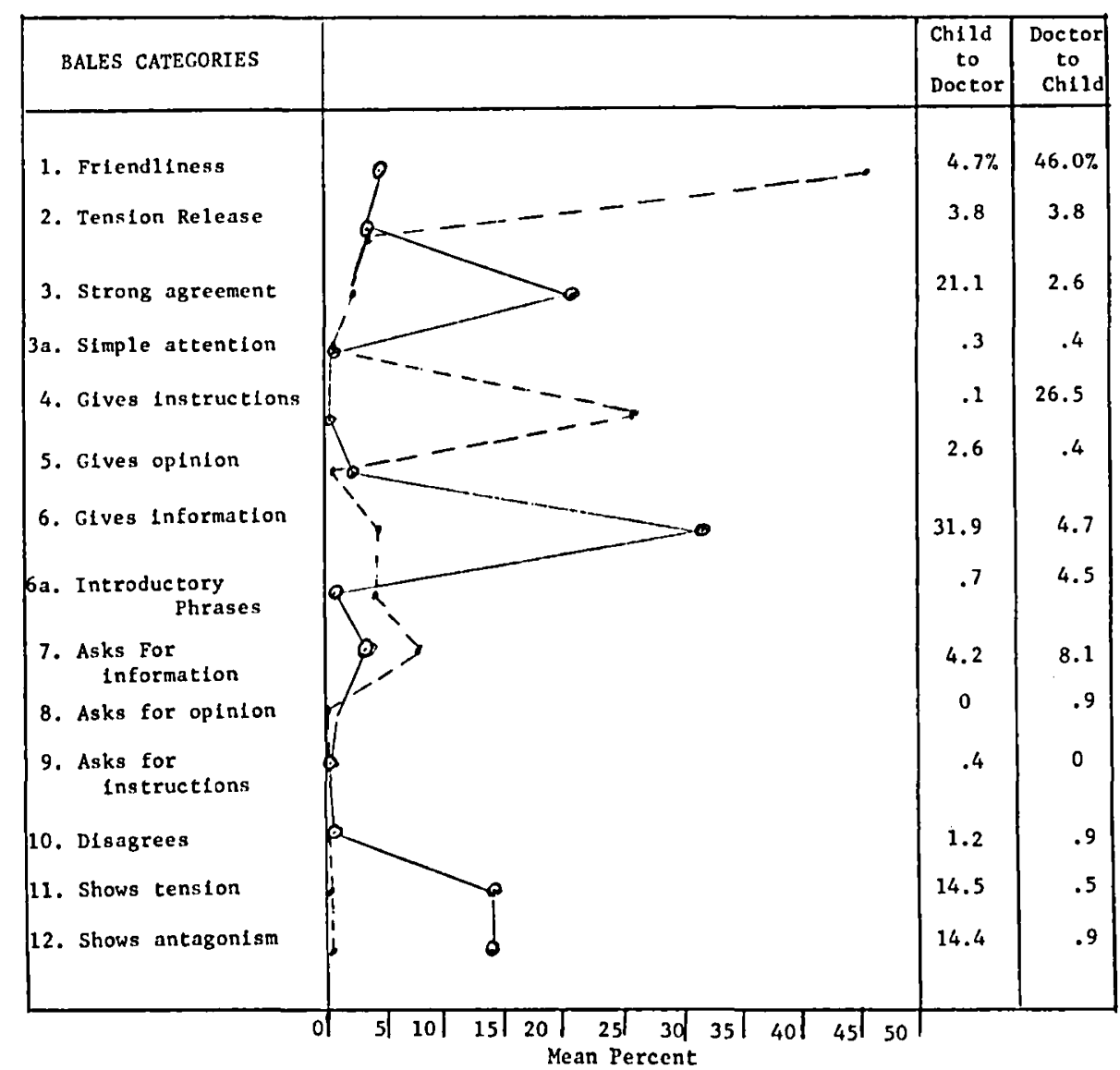

Fig. 4. Mean profile of doctor-child communication in the Bales categories. $\odot-\odot:$ Child to doctor. $\bullet--\bullet:$ Doctor to child.

\begin{tabular}{|c|c|c|c|}
\hline CONTENT CATEGORIES & & $\begin{array}{l}\text { Mother } \\
\text { to. } \\
\text { Doctor }\end{array}$ & $\begin{array}{l}\text { Doctor } \\
\text { to } \\
\text { Mother }\end{array}$ \\
\hline History & 0 & $60.3 \%$ & $34.1 \%$ \\
\hline $\begin{array}{l}\text { Physlcal } \\
\text { Examination }\end{array}$ & & 4.9 & 9.1 \\
\hline Cause & & 1.9 & 2.4 \\
\hline Diagnosis & & 6.2 & 12.6 \\
\hline Treatment & & 16.4 & 30.1 \\
\hline $\begin{array}{l}\text { Serlousness and } \\
\text { Prognosis }\end{array}$ & & 2.0 & 3.9 \\
\hline Non-medical & 10 & 8.4 & 7.7 \\
\hline
\end{tabular}

Fig. 5. Mean profile of doctor-mother communication in the content categories. $\odot-\odot:$ Mother to doctor.

Doctor to mother. 


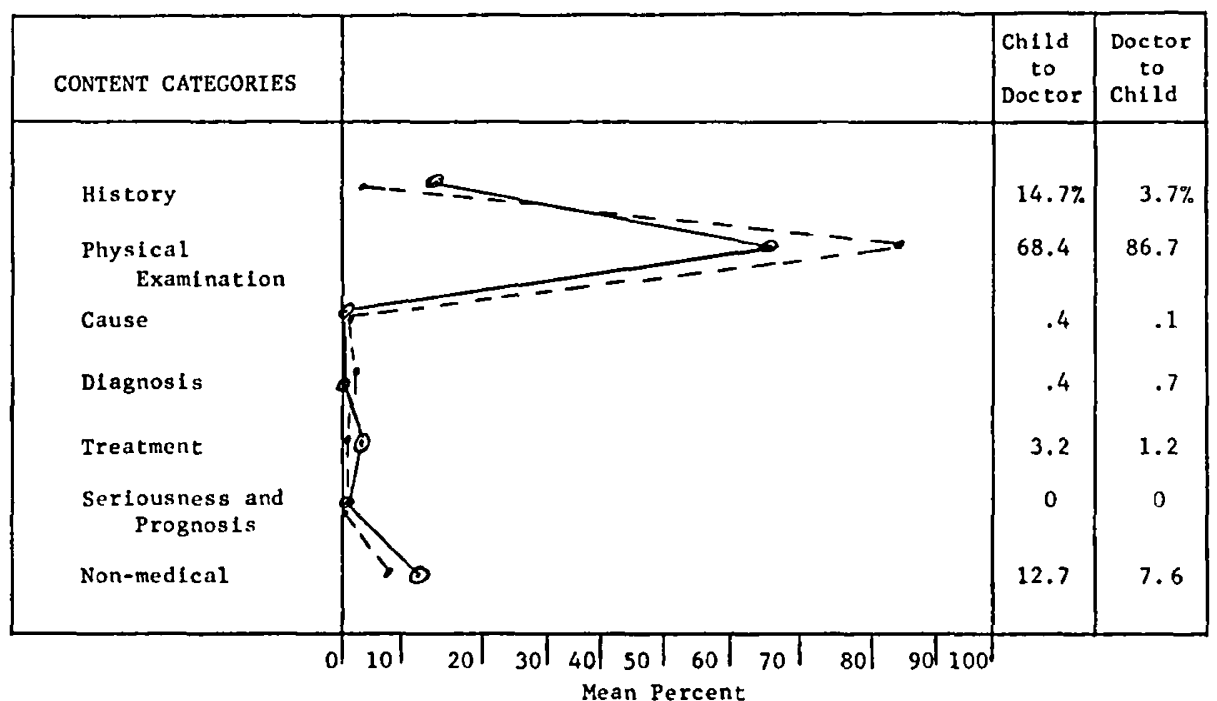

IFig. G. Mean profile of doctor-child communication in the content categories. $\odot-\odot:$ Child to doctor. $\bullet--\bullet:$ Doctor to child.
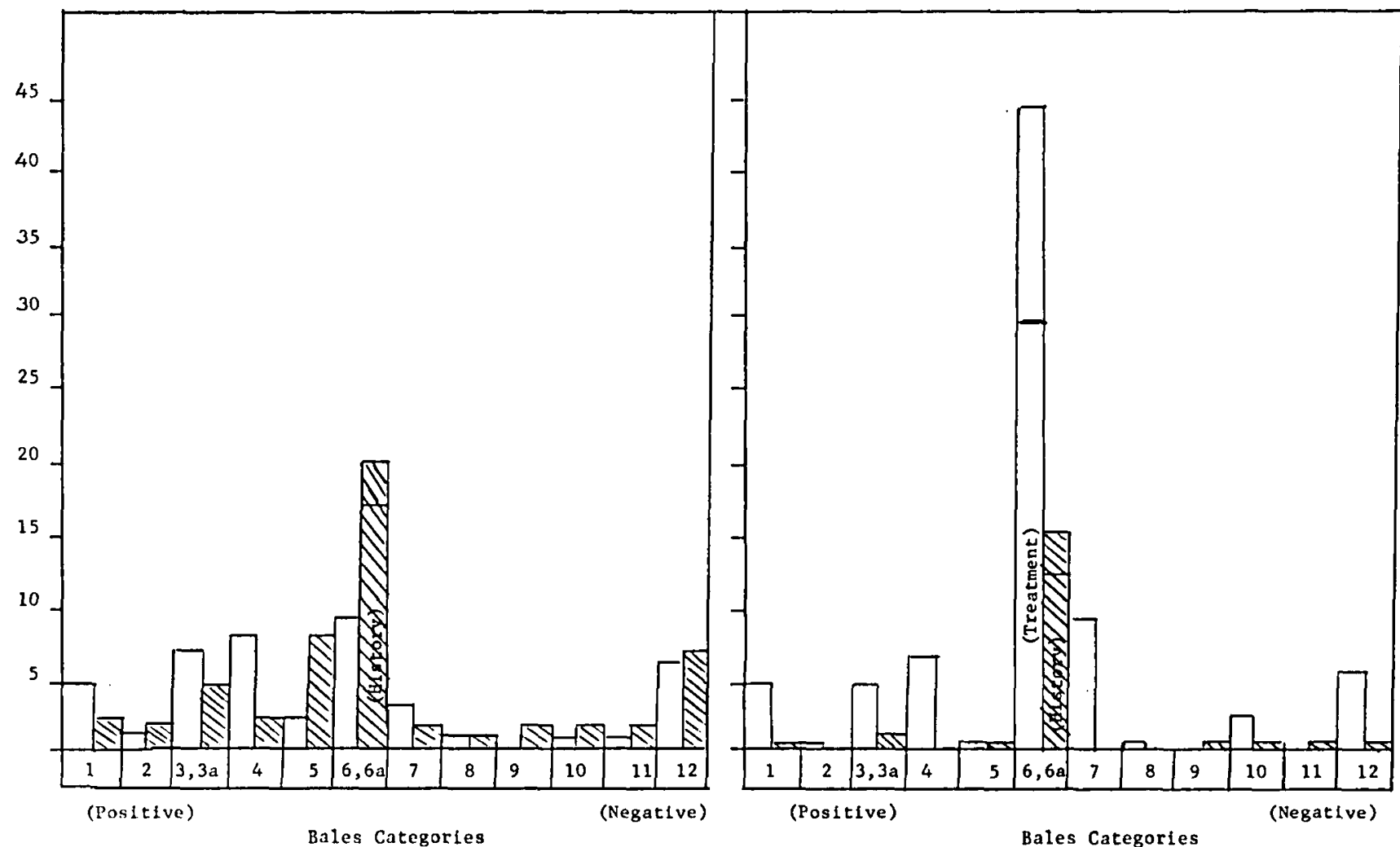

Fig. 7. Bales interaction profile for mother and doctor. Left: Case A, 244 statements by mother and 198 statements by doctor. Right: Case B, 46 statements by mother and 184 statements by doctor. Shaded areas: Mother-percentage of total. Unshaded areas: Doctor-percentage of total.

devoted to the medical history. The doctor, on the other hand, had nearly an equal amount of discussion related to history and treatment. The doctor devoted the least amount of discussion to cause and prognosis of the child's illness, yet interviews have indicated that an explanation of cause is especially important to the patients' parents and is strongly associated with their satisfaction [17]. In the doctor-child interaction (Fig. 


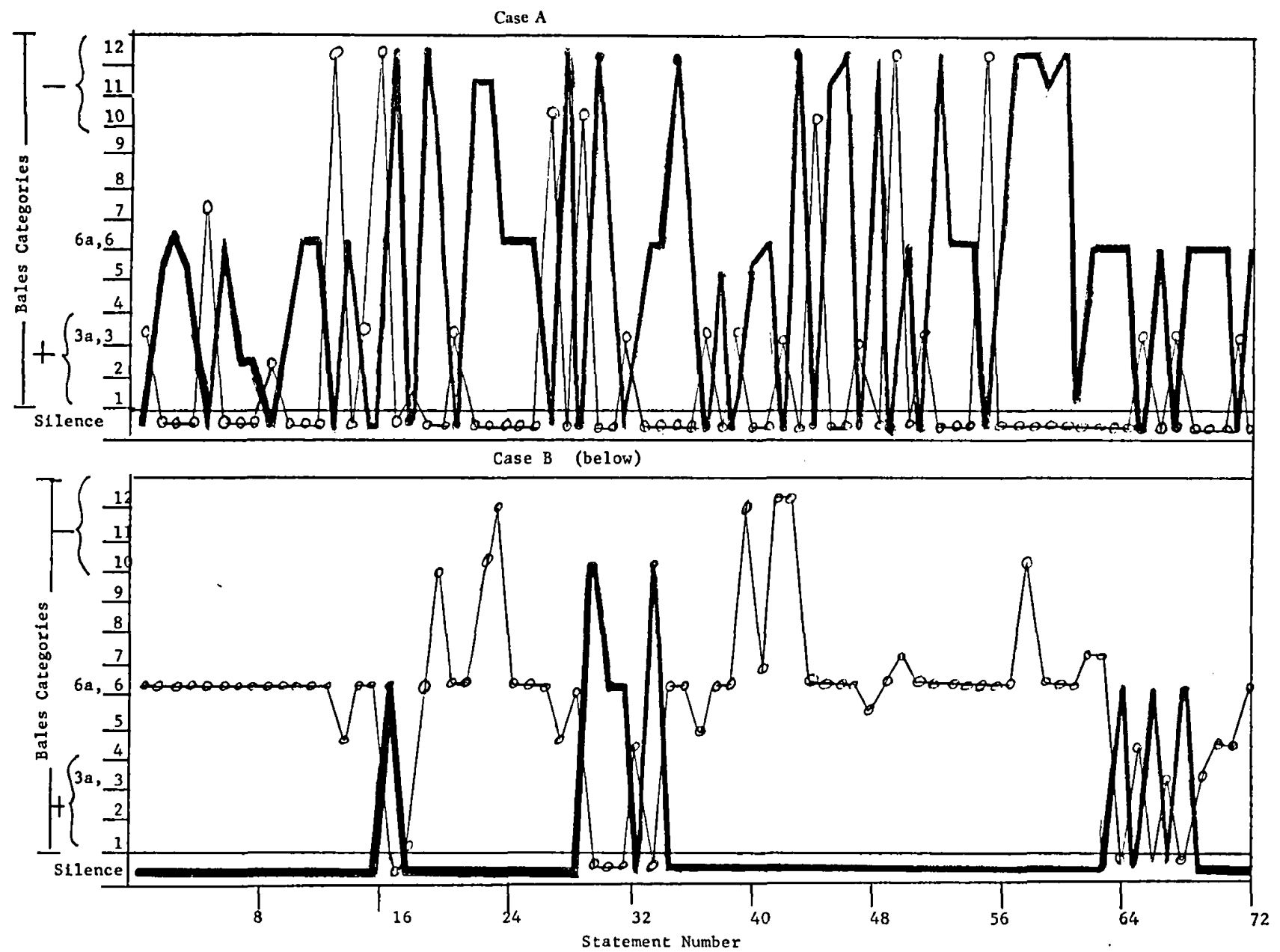

Fig. 8. Sequence interaction profile for mother and doctor. Heavy line: Mother. Thin line: Doctor.

6), practically all the discussion (86.7\%) was related to the physical examination with a small amount devoted to history-taking $(3.7 \%)$ and to general nonmedical subject matter $(7.6 \%)$.

\section{Case Illustrations}

Two cases will be briefly described and contrasted to give a clearer understanding of how this analysis can be useful in understanding an individual case. For each case there are graphs illustrating the Bales analysis (Fig. 7) and sequence of statements (Fig. 8) by mother and doctor. Case $A$ illustrates active two-way communication, with the mother's participation amounting to $55 \%$ of the total. The sequence profile (Fig. 8) shows a freely moving, back-and-forth exchange between speakers. As shown in Figure 7, the mother was especially able to verbalize her opinions and give information (categories 5 and 6 ) to the doctor while the doctor continually indicated interest, attention, and understanding (category 3). There was a mix- ture of positive and negative affect during discussions of history and treatment, indicating a high degree of emotional involvement by both mother and doctor. The mother on interview was very satisfied and compliant. She described the doctor as being friendly and reassuring, felt his attitude really inclicated that he understood her concerns and that he was especially helpful with his treatment instructions.

The pattern of conversation in case $B$ is quite in contrast to case $A$ in that of 72 statements illustrated in Figure 8 there were few exchanges between speak. ers. The doctor clearly dominated in this instance. The Bales analysis (Fig. 7) also illustrated that the mother's contribution amounted to only $20 \%$ of the total statements. The mother told the intervicwer at follow-up that she felt the doctor was "lousy," that he showed no interest, and did not relieve her worries at all. Satisfaction with this visit was rated very low, and, although she received an adequate amount of informa- 
tion relating to treatment (category 4 and 6 ), the mother was only partially compliant with the regimen.

Analysis of large numbers of individual cases using this technique of Bales analysis and sequence of statements has not been completed as yet so generalizations must be made with caution. Some fairly straight forward comparisons, however, have been completed between Balcs categories, content categories, and outcome variables.

\section{Correlations}

Only the most significant results (chi-square value of 0.05 or less) of the analysis of the interaction data in relation to patient satisfaction, compliance, and patient background are presented in this paper.

Paticnt satisfaction was not found to be related to length of interaction as measured in terms of the total number of units. Shorter interactions, however, were associated with higher compliance than long interactions (Table II). Also, mothers who tended to dominate the conversation and talk more than the cloctor expressed less satisfaction with their visit and were lower on compliance ratings (Table III). Whether doctor or mother dominated the conversation did not seem to be related to the social class or education of the mother or the nature of the illness.

The tone and process of the interaction as measured by the Bales categories were also compared with the outcome variables. The degree of emotional involvement (ratio of affectual to neutral statements) showed no correlation with outcome in that a similar percentage of highly compliant and satisfied patients were noted following interactions with little, or with a lot of affect. More affect, however, was expressed by cloctors to mothers having some college education than to those with less education.

The type of affect that was expressed by doctor and mother was found to be highly relevant to outcome. In gencral, the data support the view that expression of positive affect, i.e., being nice, is associated with greater satisfaction and compliance in the patients. As seen in Table IV, the greater the friendliness and soliclarity expressed by the doctor, the more likely the parent will be satisfied and highly compliant.

It was postulated that the doctor's conversation with the sick child would also influence satisfaction, especially since so many of the doctor's statements to the child were warm and friendly; however, there was only a slight increase in satisfaction and follow through on medical advice when the doctors devoted more time to the child (Table V).

Bales proposed a way of studying the structure of
Table II. Length of interaction and outcome

\begin{tabular}{ccccc}
\hline No. of statements & $\begin{array}{c}\text { No. of } \\
\text { patients }\end{array}$ & $\begin{array}{c}\text { Percentage } \\
\text { satisfied }\end{array}$ & $\begin{array}{c}\text { No. of } \\
\text { patients }\end{array}$ & $\begin{array}{c}\text { Percentage } \\
\text { highly } \\
\text { compliant }\end{array}$ \\
\hline $22-149$ & 94 & 78 & 85 & 53 \\
$250-1206$ & 100 & 76 & 95 & 41 \\
\hline
\end{tabular}

In the tables throughout this paper the extremes are usually compared; therefore, the number of patients will not total 283.

Table III. Speaker dominance and outcome

\begin{tabular}{llcccc}
\multicolumn{1}{c}{ Speaker dominance } & $\begin{array}{c}\text { No. of } \\
\text { patients }\end{array}$ & $\begin{array}{c}\text { Per- } \\
\text { centage } \\
\text { satisfied }\end{array}$ & $\begin{array}{c}\text { No. of } \\
\text { patients }\end{array}$ & $\begin{array}{c}\text { Per- } \\
\text { centage } \\
\text { highly } \\
\text { compliant }\end{array}$ \\
\hline $\begin{array}{l}\text { Doctor speaks more than or the } \\
\text { same as the mother }\end{array}$ & 243 & 77 & 224 & 55.5 \\
$\begin{array}{l}\text { Mother speaks more than doctor } \\
\text { Mother }\end{array}$ & 40 & 60 & 35 & 34.0 \\
\hline
\end{tabular}

Table IV. Positive affect and outcome

\begin{tabular}{ccccc}
\hline $\begin{array}{c}\text { Percentage of doctors' } \\
\text { statements with highly } \\
\text { positive tone }\end{array}$ & $\begin{array}{c}\text { No. of } \\
\text { patients }\end{array}$ & $\begin{array}{c}\text { Percentage } \\
\text { satisfied }\end{array}$ & $\begin{array}{c}\text { No.of } \\
\text { patients }\end{array}$ & $\begin{array}{c}\text { Percentage } \\
\text { highly } \\
\text { compliant }\end{array}$ \\
\hline $0-2.9$ & 84 & 66 & 80 & 38 \\
$7.5-36.4$ & 68 & 87 & 89 & 58 \\
\hline
\end{tabular}

Table $V$. Doctors' conversation with child and outcome

\begin{tabular}{ccccc}
\hline $\begin{array}{c}\text { Percentage doctor-child } \\
\text { conversation }\end{array}$ & $\begin{array}{c}\text { No.of } \\
\text { visits }\end{array}$ & $\begin{array}{c}\text { Percentage } \\
\text { satisfied }\end{array}$ & $\begin{array}{c}\text { No. of } \\
\text { visits }\end{array}$ & $\begin{array}{c}\text { Percentage } \\
\text { highly } \\
\text { compliant }\end{array}$ \\
\hline $0-4.7$ & 150 & 56.0 & 111 & 39 \\
Over 12 & 59 & 64.5 & 78 & 49 \\
\hline
\end{tabular}

interaction by combining individual categorics into meaningful units labeled "indices." For each of five indices he suggested, three scores were computed per case (mother and doctor alone and in combination), and by computer program these were tested for associations with the dependent variables. It is noteworthy that an index measuring the proportion of negative affect (disagreement, tension, antagonism) to the total amount of affect expressed between the doctor and mother had an inverse relation to both satisfaction and compliance (this is the inclex of malintegretive-expressive behavior proposed by Bales [3]) (Table VI). An increasingly negative tone for either mother or doctor was associated with increasing dissatisfaction and less high compliance. Strongly negative statements, such as hostility and antagonism, and to a lesser extent disagreements, were also associated with decreased parent satisfaction although the mother's cxpression of tension was not. The group of mothers who expressed tension but no open disagreement or hostility seemed to be distinctive in that, on interview, 
Table VI. Negative affect and outcome

\begin{tabular}{ccccccc}
\hline & $\begin{array}{c}\text { Percentage of } \\
\text { statements } \\
\text { with negative } \\
\text { affect }\end{array}$ & $\begin{array}{c}\text { No. of } \\
\text { patients }\end{array}$ & $\begin{array}{c}\text { Per- } \\
\text { centage } \\
\text { satisfied }\end{array}$ & $\begin{array}{c}\text { No. of } \\
\text { patients }\end{array}$ & $\begin{array}{c}\text { Per- } \\
\text { centage } \\
\text { highly } \\
\text { compliant }\end{array}$ \\
\hline Doctors' negative & 0 & 117 & 82 & 105 & 53 \\
affect & $0.9-69$ & 110 & 63 & 103 & 32 \\
Doctors' hostility & $0-0.7$ & 224 & 76 & 206 & 48.5 \\
& $0.7-21.3$ & 60 & 57 & 54 & 30 \\
Mothers' tension & $0-6$ & 58 & 79 & 85 & 49 \\
& $12-45$ & 76 & 72 & 92 & 42 \\
\hline
\end{tabular}

Table VII. Mothers' expression of negative affect as tension and outcome of visit

\begin{tabular}{lcccc}
\hline & $\begin{array}{c}\text { No. of } \\
\text { patients }\end{array}$ & $\begin{array}{c}\text { Percentage } \\
\text { satisfied }\end{array}$ & $\begin{array}{c}\text { No. of } \\
\text { patients }\end{array}$ & $\begin{array}{c}\text { Percentage } \\
\text { highly } \\
\text { compliant }\end{array}$ \\
\hline $\begin{array}{l}\text { Mothers expressing ten- } \\
\text { sion }\end{array}$ & 104 & 82 & 94 & 53 \\
Remainder of sample & 180 & 65 & 166 & 40 \\
\hline
\end{tabular}

Table VIII. Agrement and outcone

\begin{tabular}{|c|c|c|c|c|}
\hline $\begin{array}{l}\text { Percentage of } \\
\text { mothers' statements, } \\
\text { arreement, and } \\
\text { ucknowledgments }\end{array}$ & $\begin{array}{c}\text { No. of } \\
\text { patients }\end{array}$ & $\begin{array}{l}\text { P'ercentage } \\
\text { satisfied }\end{array}$ & $\begin{array}{c}\text { No. of } \\
\text { patients }\end{array}$ & $\begin{array}{c}\text { Percentage } \\
\text { highly } \\
\text { compliant }\end{array}$ \\
\hline $0-15$ & 106 & 67 & 99 & 40 \\
\hline $24-87.5$ & 97 & 82 & 95 & 47 \\
\hline
\end{tabular}

Table IX. Questions during the visit and outcome

\begin{tabular}{lccccc}
\hline & $\begin{array}{c}\text { Percentage } \\
\text { questions }\end{array}$ & $\begin{array}{c}\text { No. of } \\
\text { patients }\end{array}$ & $\begin{array}{c}\text { P'ercentage } \\
\text { satisfied }\end{array}$ & $\begin{array}{c}\text { No. of } \\
\text { patients }\end{array}$ & $\begin{array}{c}\text { Percentage } \\
\text { highly } \\
\text { compliant }\end{array}$ \\
\hline Mothers' & $0-2$ & 87 & 79 & 74 & 49 \\
& $6-22$ & 111 & 66 & 81 & 43 \\
Doctors' & $0-33$ & 93 & 75 & 86 & 53.5 \\
& $45-87$ & 110 & 68 & 98 & 38 \\
\hline
\end{tabular}

Table $x$. Nonmedical, general content and outcome

\begin{tabular}{ccccc}
\hline $\begin{array}{c}\text { percentage of general } \\
\text { nonmedical statements }\end{array}$ & $\begin{array}{c}\text { No. of } \\
\text { patients }\end{array}$ & $\begin{array}{c}\text { Percentage } \\
\text { satisfied }\end{array}$ & $\begin{array}{c}\text { No. of } \\
\text { patients }\end{array}$ & $\begin{array}{c}\text { Percentage } \\
\text { highly } \\
\text { compliant }\end{array}$ \\
\hline $0-4.4$ & 94 & 66 & 89 & 35 \\
$9-37$ & 85 & 86 & 81 & 55
\end{tabular}

they also expressed less dissatisfaction and reported less noncompliance than the remainder of the sample (Table VII).

As illustrated in Table VIII responses from the mother showing agreement with and understanding and acknowledgement of what the doctor was saying were correlated with satisfaction but contrary to the finclings of Davis [10, 11] were not correlated with compliance. It would seem that no matter how much the mother verbally agrees to comply or shows understanding, this is no criterion for predicting compliance. The relation of so-called "yes" mothers (those high in agreements) to high satisfaction ratings may suggest a limitation of interview technique. Mothers who express a lot of agreement, acknowledgement, and understanding during the interaction also may find it difficult to express dissatisfaction on interview.

In general, the way mother and doctor phrased their questions and statements was not related to the outcome variables. Furthermore, whether the doctor gave instructions in a permissive or authoritarian way seemed to have no relation to the degree to which the mother followed through. On the other hand, it seemed that receiving information made for patient satisfaction and compliance because mothers who were asked more questions, or had to ask for more information had a less favorable response to the visit (Table $\mathrm{IX})$. There was increased compliance by parents when doctors gave more information than when doctors asked a greater proportion of questions. (The difficulty of communication index proposed by Bales [3] is defined as number of questions per number of questions and number of statements.)

In general, it appeared that the doctor largely controlled the subject matter; it was the number of statements by the doctor in the various content areas that proved most related to outcome variables.

A consistent finding in the study was that visits containing some conversation of a general or nommedical nature were associated with more satisfaction and compliance (Table X). This "nonmedical" content category was designed to include any general conversation not specifically related to the medical problem, such as greetings, talking to or about other children in the family, and other purely social interchange. Since many of the statements in this category also showed positive affect, however, it cannot be determined at this time whether outcome is influenced by the social conversation or by the warmth and friendliness of the doctor, expressed in relation to all subject matter.

An original hypothesis was that a longer, more thorough history-taking period, in which the mother was allowed to "get everything off her chest," would result in greater satisfaction and compliance. Also, many doctors believe the history to be the most important part of the interaction and the one with which they take the greatest care. In this study, however, the time devoted to history taking was found to correlate negatively with satisfaction and compliance; generally, 
cases with longer histories were associated with more dissatisfaction and lower compliance (Table XI). This may mean that a long history-taking process reflects difficulty in communication as perceived by the mother.

Consideration was given to the relation between the subject matter discussed and the most frequent diagnoses represented in the sample-car infections, colds, skin problems, and gastrointestinal upsets. Although it might be thought that longer histories would necessarily be associated with more complicated diagnoses, this was not found to be the case. Rather histories of all lengths were recorded with each type of illness.

Increased satisfaction seemed to be associated with the extent to which the doctor discussed the cause of the illness (Table XI), but this association could not be documented statistically since in 110 of 284 cases there was no discussion of cause whatsoever. The amount of discussion regarding the examination, diagnosis, treatment, or seriousness and prognosis did not correlate significantly with satisfaction, although there was a trend toward higher compliance in cases having more discussion devoted to diagnosis. Contrary to expectations, the amount of discussion about treatment by the doctor was not related to compliance.

The only content factor which bore a highly significant relation to social class was the cloctor's discussion of diagnosis; more discussion was directed by doctors to patients in the middle and lower classes than to the higher social classes.

\section{Discussion}

The findings presented in this report are one of several attempts by the present research team to document the factors that contribute to effective communication between physicians and patients. Some of the results of the studies presented here are of interest primarily in that they describe the process of interaction more objectively. These descriptions are sufficiently clear so that comparisons can be made between different kinds of communication. For instance, in the case of pediatric practice, the physician's conversation with the child patient himself can be compared with his manner in respect to the patient's mother. It can be noted that friendly, warm conversation makes up almost half of the pediatrician's interaction with the child, but amounts to less than $6 \%$ of his conversation with the mother. When it is considered that so much of the effectiveness of pediatric care of ambulatory patients is directly dependent upon cooperation and understand-
Table XI. Content and outcome

\begin{tabular}{cccccc}
\hline & $\begin{array}{c}\text { Percentage } \\
\text { of } \\
\text { statements }\end{array}$ & $\begin{array}{c}\text { No. of } \\
\text { paticnts }\end{array}$ & $\begin{array}{c}\text { Percentage } \\
\text { satisfied }\end{array}$ & $\begin{array}{c}\text { No. of } \\
\text { patients }\end{array}$ & $\begin{array}{c}\text { Percentage } \\
\text { highly } \\
\text { compliant }\end{array}$ \\
\hline History & $0-26$ & 91 & 78 & 83 & 52 \\
Cause & $39-83$ & 93 & 64 & 83 & 39 \\
& $0-0.9$ & 124 & 65 & 113 & 50 \\
& $1-25$ & 160 & 77 & 85 & 40 \\
\hline
\end{tabular}

ing on the part of the mother, this absence of warmth expressed to the mother herself is alarming. The tendency for pediatricians to identify with the child paticnt and to consider the parent as a somewhat unwelcome intruder in relation to his patient is well known, but the present report is one of the first instances in which this trend is documented and quantified.

Another descriptive finding related simply to the content of the conversation between the doctor and the patient's parent. Very few words are devoted to anything but strictly medical cliscussion, yet there is a statistically significant relation between the amount of social, nonmedical conversation and the outcome of the consultation, not only in respect to patient satisfaction but also in follow through on the medical advice received from the doctor.

Some common concepts concerning doctor-patient interaction are challenged by the results of the investigation on which this report is based. Most doctors believe that they do more listening to their patients than talking. Yet, admitting that there are some extremely garrulous patients whom all remember but too vividly, it was found in the present sample that physicians did more talking than did the mothers. No relation between longer consultation and favorable outcome of the medical visit was demonstrated. This in itself came as a surprise to many because it has so often been said that all health professionals would be more effective, "if only they had more time to spend with their patients." In earlier reports by this research team it has been stated that the time of interaction in minutes, as such, did not influcnce the outcome. Now it can be added that the amount of talking by the doctor or patient, as such, also could not be shown to influence the results of the medical visit. Does this mean that, "listening to the patient," in itself, is not as helpful as it always has been thought to be? Not necessarily. All that can be claimed on the basis of this study is that the length of time that the doctor is in the same room with the patient, while the patient is talking, does not influence the patient's responses. True listening probably involves more than that. This also ap- 
plies to the findings obtained in respect to the content category in the analysis referred to as "medical history." It might have been assumed that the presence of a long history in itself would indicate that the patient had had a chance to express her concerns more fully and would consequently leave her more satisfied and likely to follow the advice. This was not the case. As a matter of fact, if anything, excessively long historics tended to be associated with dissatisfaction, nor did extra long interactions lead to more satisfaction. Although this cannot be backed up statistically, in looking at individual cases it would appear that perhaps long histories reflect difficulty in communication rather than being a sign of effective communication.

In this study, the amount and kind of affect expressed during the consultation by the physician was compared with the amount voiced by patient's mother. There was found to be a significant relation between the type and amount of emotion expressed by doctor and mother and the outcome of the consultation. Larger amounts of hostility and expression of other negative affect were associated with negative outcome. More positive affect and greater friendliness and soliclarity were generally associated with greater satisfaction and better follow through on medical advice. In some ways this seems a clocumentation of the obvious except for some earlier suggestions by other workers [ 7 , 9] that increased social distance and less friendliness between physician and patient might lead to better follow through on advice given, perhaps, owing to the greater authority vested in the physician.

It is also noteworthy that, in general, the mothers expressed significantly more negative affect than do the physicians, and that this negative affect tends to be more in the direction of tension than out-and-out hostility and antagonism. Expressions evidencing tension constitute, on the average, about $10 \%$ of the mother's statement and may contribute as much as $45 \%$ of the mother's statements in individual cases. The doctor, although he shows a certain amount of disagreement with the mother, shows very little tension and only a small amount of hostility and antagonism, which incidentally is equivalent to that of the mother. In simple summary it would appear that both mother and doctor occasionally express reciprocal antagonism with each other but that the outstanding negative feclings experienced during a consultation involving a sick child are experienced and expressed by the mother. It is she who is uncomfortable and tense. This becomes especially noteworthy in light of the fact that there is so little solidarity or reassurance to her, expressed by the doctor.
A related finding is that the percentage of total statements expressing alfect of any kind is definitely higher for the mother than for the physician, suggesting that a medical visit with a sick child generally is a more emotionally charged experience for a mother than for her cloctor.

Initially, it had been expected that the opportunity to ask many questions of the physician would make patients feel more satisficd with their consultation; however, the study showed that those mothers who did ask many questions tended to be less satisfied. Similarly, one might have assumed that a patient would perceive that a physician who asks her many questions was evincing interest in her and this might make her feel satisfied. Inspection of inclividual cases offered some insight into the basis for these findings. It would appear that patients prefer a "giving" doctor who freely offers information to one who makes it necessary for them to ask for it specifically; that is, being asked questions by the physician tended to be associated with a doctor-patient relation where the mother felt that she was doing the giving and did not get as much from the physician for herself.

Asicle from the descriptive and correlative findings presented here, the implications of applying a nethod such as Bales Interaction Process Analysis [3] to the situation that is represented by a medical consultation needs to be considered. The Bales method was not designed primarily for elucidation of an interaction between just two persons who are addressing themselves to the solution of one specific medical problem. Instead, there was more empliasis on subtler, affective, interpersonal relations: hence the highly detailed, descriptive categories and the sometimes baffling indices and analytical approaches which have not been completely detailed here. As anticipated, only portions of the methodology proved relevant to the data under consideration. Still, the Bales method was one of the few prior attempts at quantifying and measuring what had heretofore been subjected only to intuitive appraisal. It also made possible some comparisons between the interaction process as perceived by the interactors and as analyzed with these more objective methods. Having documented $[12,17]$ that in many respects the interaction process was quite appropriately mirrored in the mother's perceptions, there would be no need for such detailed coding in the future. There are a limited group of significant variables, however, which were isolated and noted for the first time by application of the Bales method that should justifiably be searched for in future attempts to describe and 
measure the verbal communication between doctor and patient.

\section{Literature Review}

The subject areas most related to doctor-patient behavior are role theory and communication theory, especially Bales Interaction Process Analysis and its application.

\section{Doctor-Patient Roles}

Sociological views of the doctor-patient relation contribute greatly to the general theoretical framework for the present research. The concept of role has been especially useful "because it offers a means of studying both the individual and the collectivity within a single conceptual framework" [13]. Although the consultation between physician and patient can be considered within the realm of small group interaction, it is atypical of most other small groups in that the members have certain predetermined roles or patterns of behavior as well as a common goal. As characterized by Parsons [22], the doctor is sought out by the patient to make a diagnosis and to indicate what treatment is necessary for "wellness." In return, the patient is expected to cooperate by giving information to the doctor and by following his recommendations. The sick person, in playing the "sick role," is unable to fulfill his social obligations, and the physician, in applying his knowledge to cure the condition, helps restore this imbalance in society. The physicians' acts are of two types, "instrumental," having to do with technical aspects of treatment, and "expressive," having to do with the emotional and psychological aspects of patient care.

Since Parsons' original application of role concepts to illness behavior, numerous contributions have been made to elaborate doctor-patient behavior patterns and role theory in gencral. Ccrtainly one of the finest resumés of the history, structure, and properties of role theory is the work of Biddle and Thomas [6]. Not until 1966, however, were Parsons' assumptions about the sick role, as well as possible sociocultural variations, tested empirically [13]. In that study, Gordon distinguished two types of roles relating to illness based on behavioral expectations, whether the patient's prognosis is serious and uncertain (the "sick role") or whether the prognosis is nonserious and certain (the "impaired role").

Bloom [7] and others [16, 19] also inferred certain expectations from the social roles of the physician and patient. Both doctor and patient are scen as being influenced by their respective subcultures and by the social status ascribed to them by the larger society. Doctors and medical students themselves view the doctor as the one in charge, deriving authority from the patient's consent and from societal expectations [21]. Most satisfaction-dissatisfaction and problems were seen as part of the affective side of the doctor-patient relation, and the doctors most frequently reported dissatisfaction from lack of control over difficult patients.

Social distance between doctor and patient is a commonly noted source of communication difficulty. Also some believe the doctor's role to be particularly structured and stereotyped [15].

\section{The Study of Communication}

There have been numerous attempts to study doctor-patient communication. One of the more indirect approaches has been the use of follow-up interview. A serious limitation of this method, however, is the lack of recorded interaction for more direct analysis. Such a study by Ambuel [2], consisting of 97 interviews with mothers after clinic visits for their sick children, revealed that inadequate information was given regarding cause of illness, reason for the return appointment, expected cost and action of the prescription given. The mothers were able to give more specific information when it related to something they must do rather than why they should do it.

The need for and lack of explanations have also been reported by Reader [23], who found that patients scemed to have a great need for explanations but made no particular effort to get information from the doctors nor criticized doctors for not giving information, perhaps suggesting that they in fact did not expect such explanations. Hospitalized patients in Cartwright's study [9] reported that information was difficult to obtain, especially regarding the cause or nature of illness and the likelihood of recurrence. More dissatisfaction was expressed by patients who said they had to ask than by those who said people gave them information freely. Those who neither asked nor were told were the most dissatisfied. Diffidence by patients in asking for information was attributed to problems of language and doctor-patient social distance.

Another investigator [20] attempted to relate doctors' feelings, as reflected in their speech during an interview, to the degree of success in referring alcoholic patients for continued treatment. The analysis involved auditing of tape recordings, content-filtered tape recordings (tone only), and transcripts of the in- 
terviews. Those doctors who were judged to be less angry and more anxious were more effective.

Other attempts have been made to analyze interaction more directly through observation or tape recordings. An article by Weick [2.1] contains a careful elaboration of problems and techniques of observation. He discussed settings and methods for observation, problems of observer interference, and the various types of observable verbal and nonverbal behavior. The study by Lennard and Bernstein [18] of structure and process of verbal interaction between psychotherapist and patient using a system of categories (e.g., ( $(1)$ indicates listening, passively encourages more; (2) actively encourages more; or (3) limits patient to single subject area) showed patient satisfaction to be associated with their expectations and the absence of strain during communication. Zalbarenko [25] developed methods of direct observation of doctor-patient interaction but these were purely descriptive.

Davis $[10,11]$ applied a modified form of the Bales instrument to tape recordings of patient visits in a general medical clinic. His study of doctor-patient communication was similar to the present one except that he used an adult population, only one outcome variable (compliance), and two visits per patient. Interaction categories were found to be related to compliance on the second visit only. The giving of information by the doctor and patient agreement, tension release, and questions seeking the doctor's opinion were those aspects of communication associated with compliance. Noncompliance was observed more often in patients who expressed tension or who gave their opinions, and in response to doctors who disagreed or asked for information without giving any feedback. By means of factor analysis 10 types of doctor-patient communication were described, $e$.g., "active patient-passive cloctor."

Other adaptations of Bales' analysis include that of Adler and Enelow [1], who designed a scale to fit the special characteristics of the communication between a patient and a psychotherapist. Also, Borgatta [8] reorganized the Bales categorics to allow for the intensity of responses and for greater differentiation of the communication process. His system limits the neutral categories while expanding the positive and negative ones (from 8 to 14), making for a more accurate and specific analysis of interaction.

The literature stresses the increased attention given to the study and scientific evaluation of interaction among people. Although development has been hampered by the lack of measuring techniques, advances have been made in this area. At this time certainly the most basic and most generally applicable approach is Bales analysis [3]. Although this procedure was originally designed for analyzing interaction within small groups by having observers watch, listen, and code the process through one-way windows, it has been more widely adapted and utilized than any other. More recently, Bales further developed the original categories theoretically, in terms of how an individual is rated by others on three dimensions: power, affection, and contribution to the group [4]. There has also been some attempt to set up norms for the Bales categories [5].

\section{Conclusion}

In summary, the application of the complex method of Bales to analysis of the verbal communication between doctor and patient yicleled a wealth of descriptive, qualitative, and quantitative data and made possible a few clinical correlations. Outcome of the medical communications, in terms of the patient's satisfaction and follow through on melical advice, was favorably influenced by having a physician who was friendly; expressed solidarity with the mother; took some time to discuss nonmedical, social subjects; and showed an interest in her and gave her the impression of offering information freely, without her having to request it, or feeling excessively questioned by him. More total affect, and especially most negative affect, was experienced and expressed by mothers during a medical visit than by doctors and the total amount of negative affect expressed by both could be correlated with an unfavorable outcome of the consultation.

\section{References and Notes}

1. Adter, L., ANd ENelow, $A$. J.: $A$ scale to measure psychotherapy interaction (Department of Psychiatry, University of Southern California School of Medicine, Los Angeles, 1964, umpublished.)

2. Ambuel, J., Cebulta, J., Whtt, N., and Crowne, D.: Doctormother communications, a study of information communicalted during clinic visits for acute illness (Ohio State Univer. sity, Columbus, 1964, unpublished.)

3. BAt.es, R. F.: Interaction Process Analysis (Addison-Wesley Press, Cambridge, 1950).

4. BMLES, R. F.: Interaction process analysis. In: D. I. Sills: International Encyclopedia of The Social Sciences, Vol. 7, p. 465 (Crowell-Collier and Macmillan, New York, 1968).

5. Bales, R. F., AND IARE, $A$.: Diagnostic use of the interaction profile. J. Soc. Psychol., 67: 239 (1965).

6. Bidde, B., AND THomas, E.: Role Theory (John Wilcy \& Sons, New York, 1966).

7. Broom, S.: The Doctor and Ilis Patient-A Sociological Interpretation (Russcll Sage Foundinion New York. 1963). 
8. Bokg,AтrA, E. F.: A systematic study of interaction process scores, pecr and self-assessments, personality and other variables. Genet. Psychol. Monogr., 65: 219 (1962).

9. Caktwright, A.: Human Relations and Hospital Carc (Routledge \& Kegan, Paul, London, 1964).

10. DAvis, M. S.: Physiologic, psychological and demographic factors in patient compliance with doctors' orders. Med. Carc, 6: 115 (1968).

11. Davis, MI. S.: Variations in patients' compliance with doctors' advice: Enpirical analysis of patterns of communication. Amer. J. Public llealth, 5s: 274 (1968).

12. Francis, V., Korsci1, B., AND Mokkis, M.: Gaps in doctor-patient communication: Paticnts' response to medical advice. New Engl. J. Med., 280: 535 (196!)).

13. Gokmon, G.: Role Theory and Illness (College and University Press, New Ilaven, Comn., 1966).

14. GozzI, E., MorkIs, M., AND Korsch, B.: Gaps in doctor-paticht communication: Implication for nursing practice. Amer. J. Nursing, 69: 529 (1969).

15. Kabusitu, C.: Social distance between client and professional. Amer. J. Sociol., 67: 517 (1962).

16. Koos, 1.: The Health of Regionville (Columbia University Press, New York, 1954).

17. Korsch, B., Gozzi, E., AND Francis, V.: Gaps in doctor-patient communications: Doctor-patient interaction and patient satisfaction. Pediatrics, $42: 855$ (1968).

18. Lennaki, H. L., And Bernstein, A.: The Anatomy of Psycliotherapy (Columbia University Press, New York, 1960).

19. Mrcinsic, D.: Role expectations and communication in the therapist-patient relationship. J. Health Hum. Behav., 2: 190 (1961).

20. Milmoe, S., Rosenthal, R., Blane, H., Chafetz, M., and Wor.F, I.: The doctor's voice: P'ost dictor of successful referral of alcoholic patients. J. Abnorm. Psychol, $72: 78$ (1967).
21. OKT, R., Ford, A., AND Liske, R.: 'The doctor-patient relationship as described by physicians and medical students. J. Ilealth I Ium. Behav., 5: 25 (1964).

22. Parsoss, T.: Illness and the role of the physician. J. Orthopsychiat., 21: 452 (1951).

23. Reader, G. G., Pratt, L., IND Mtob, M. C.: What patients expect from their doctors. Mod. IIosp., 89: 88 (1957).

24. Wrick, K. E.: Systematic observational methods. In: G. Lindzey and E. Aronson: The llandbook of Social Psychology, Vol. 2, p. 357 (Addlison-Wesley Publishing Company, Reading, Mass., 1968).

25. ZaвnRfino, L.: Some thoughts on cducational evaluation, p. 19 (A.P.A. Committce On Psychiatry and Medical Practice, Proceclings of The Third Collegium For Postgraduate Teaching of P'sychiatry, Miami Beach, 196-1).

2(i. Supported by US Children's Bureau Grant no. H-10; Department of Health, Education, and Welfare Grant no. IIS 00381-02; and the California State Department of Public Health.

27. Dr. Korsch is the recipicnt of National Institutes of Health Research Career Development Award no. 5-K3-HO-28, 297.

28. We are indebted to Elaine Aley and the other rescarch team members for valuable assistance in coding of the data, to the staff of Childrens Hospital of Los Angeles for cooperation, and to Ray Mickey, PhD., and Miss Coralce Yale for collaboration in data processing. Computing assistance was ob. taincel from the IIcalth Science Computing Facility, University of California, Los Angeles, sponsored by National Institutes of Health Grant no. FR.3.

29. Requests for reprints should be addressed to: Barbara Korsch, M.D., Childrens Hospital of Los Angeles, 4650 Sunset Boulevard, Los Angeles, Calif. 90027 (USA).

30. Accepted for publication October 6, 1970. 